\section{ATAXIC NEUROLOGICAL SYNDROME FOUND IN TANGANYIKA}

BY

\section{R. W. HADDOCK, M.D., M.R.C.P., D.T.M.\&H. Medical Specialist} G. J. EBRAHIM, M.B., $\underset{\text { Medical }}{\text { Ffficer }}$.R.F.S., M.R.C.P.Ed.

AND

B. B. KAPUR, M.B., B.S. House-physician

From the Princess Margaret Hospital, Dar-es-Salaam, Tanganyika

Ataxic neurological syndromes, usually attributed to nutritional deficiencies, have been described in the West Indies by Scott (1918), in the Middle East by Spillane (1947), in P.O.W.s from Rangoon by Garland (1946), in West Africa by Money $(1958,1959)$, and in Arabia by Walters (1953). Sensory ataxia, optic atrophy, and nerve deafness were features of these syndromes.

Seven similar cases from the Rufiji district of Tanganyika are recorded because (1) we believe this to be the first series of such cases reported from East Africa -many more cases may be seen owing to the present food shortages; and (2) the series shows some variations from those previously described and we have been able to study these patients fully in hospital.

\section{Clinical Picture}

The patients were adult Africans, five men and two women, from the Rufiji district, which is coastal, poor, and backward. Rice and maize meal are the staple diet and the rice is often overpounded at home to make it whiter. Rice was the main article of the diet for six patients and the seventh ate cassava and bananas. In 1961 drought followed by floods caused serious food shortage.

The patients gave a history of paraesthesia or numbness in the legs, soon followed by disabling ataxia. The onset was sudden, occurring after a few days' fever in two cases; in the others it was gradual. The illness began in the sixth month of pregnancy in one patient, who improved spontaneously after delivery. In the others no improvement occurred until hospital treatment was begun some weeks after the onset. All the patients were unable to feel the ground properly when walking (two described it as like walking on mud). We think that this diminution of deep pressure sense in the soles was probably largely responsible for their ataxia. Constipation in four patients may have been due to inactivity, but it has been described in nutritional neuropathy by Buchanan (1932) and Money (1959). Sphincter disturbances were absent. The symptoms and signs are summarized in the Table (Case 7 is not included as the patient, a woman aged 20 , was recovering on admission).

The patients appeared to be fairly well nourished by local standards. Nutritional mucocutaneous changes were not seen. All were grossly ataxic except the woman in the recovery phase. Their gait was wide-based and some lifted their feet high and stamped them down. All watched their feet while walking. Motor power was well preserved and plantar responses were flexor, although Case 2 had abnormally brisk reflexes.
Objective sensory signs were less marked than expected from the degree of ataxia. Deep pressure sense in the soles was diminished in all, but joint sense seemed fairly normal. Definite signs of cerebellar dysfunction were not found. Co-ordination in the legs was rather poor in four. Audiograms showed appreciable hearing loss in the lower frequencies in one case and in the speech range in another. Repeat audiograms two months later showed moderate and slight improvement respectively. Prolongation of the cold caloric time may have indicated damage to the vestibular division of the eighth nerve. Optic-disk pallor was present in four patients and diminished visual acuity in four; accurate perimetry proved impossible. The cranial nerves were normal apart from the second and eighth. The patients were normal mentally except for one woman who was agitated and paranoid for two days.

\begin{tabular}{|c|c|c|c|c|c|c|}
\hline \multicolumn{7}{|c|}{ Summary of Cases } \\
\hline & $\underset{1}{\text { Case }}$ & $\underset{\mathbf{2}}{\text { Case }}$ & $\underset{3}{\text { Case }}$ & Case & $\underset{5}{\text { Case }}$ & Case \\
\hline 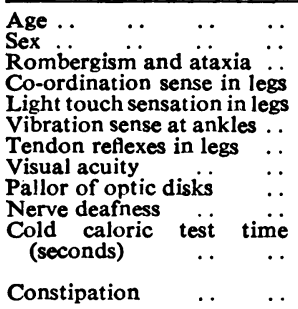 & $\begin{array}{c}25 \\
M \\
\pm \\
\pm \\
\pm \\
o \\
6 / 96 / 12 \\
+ \\
++ \\
75\end{array}$ & $\begin{array}{c}60 \\
M \\
+ \\
+ \\
+ \\
+ \\
++ \\
+ \\
+ \\
25\end{array}$ & $\begin{array}{l}30 \\
\mathbf{M} \\
\pm \\
= \\
= \\
\mathbf{0} \\
+ \\
+\end{array}$ & $\begin{array}{c}40 \\
\mathrm{M} \\
+ \\
+ \\
+ \\
+ \\
0 \\
6 / 96 / 12 \\
\pm \\
\pm \\
20 \\
20\end{array}$ & $\begin{array}{l}50 \\
\mathbf{M} \\
+ \\
\pm \\
+ \\
+ \\
+ \\
+ \\
0 \\
0 \\
35\end{array}$ & $\begin{array}{l}25 \\
F \\
\pm \\
\pm \\
\overline{0} \\
+ \\
++ \\
45\end{array}$ \\
\hline
\end{tabular}

$++=$ Exaggerated or marked. $+=$ Present or normal. $-=$ Diminished $\pm=$ Doubtful. $0=$ Absent.

Normal cold caloric test time $<30$ seconds-until onset of nystagmus.

The arms were normal except for absence of reflexes when these were absent in the legs. Other systems showed no gross abnormalities. The disease seemed to affect posterior column functions in the legs and sometimes the optic and vestibulo-cochlear nerves.

Special Investigations.-C.S.F. examination, blood Kahn test, E.C.G., E.S.R., full blood count, and serum protein examination were done in all cases. One patient had a moderate hypochromic anaemia and a positive blood Kahn reaction, two had raised sedimentation rates, and one had a raised C.S.F. pressure not found on repeat lumbar puncture. Otherwise these investigations were negative. Antibodies to certain Arbor viruses were present in the patients' sera, but no one antibody type was common to all. F.T. meals were normal in three patients.

\section{Treatment and Progress}

All patients were treated in hospital with vitamin $B_{1}$ (75 mg. daily) and vitamin B co. (2 tabs. t.d.s.). Recovery was slow over the course of several weeks and has not always been complete. During recovery three patients complained of burning sensations in hands and feet.

Case 5 recovered almost completely in six weeks; Case 3 recovered completely in three months. Other patients had made partial recoveries in six to eight weeks. Progress was slow, but did occur after failure to improve at home for some weeks or months. We think that this apparent response to improved diet and vitamins of the B group supports a nutritional aetiology. Onset after fever may be due to increased metabolism and vitamin utilization. Although all patients denied taking alcohol or native medicines a toxic cause cannot be excluded. 


\section{Discussion}

The present series of cases may be briefly compared with previously reported cases of a similar type. Scott (1918) described "central neuritis" from Jamaica. This syndrome included pains and paraesthesia in the feet and legs, ataxia, and deterioration in vision and hearing. This disease was preceded by stomatitis, conjunctivitis, and malaise, and was regarded as toxic in origin. Since then other works have published accounts of similar neurological abnormalities in association with mucocutaneous lesions such as cheilosis, angular stomatitis, and scrotal dermatitis (Bradley, 1929 ; Stannus, 1936). In Malaya, Pallister (1940) described ataxic paraplegia and visual dimness but no deafness. Spillane (1947) gave a full acount of a syndrome of retrobulbar neuritis, deafness, and ataxia in German P.O.W.s in the Middle East. These cases were similar to those of the present series, but burning sensations of the feet were prominent, reflexes were generally exaggerated, and constipation was not noted. This syndrome was considered to be a nutritional deficiency disease.

Money $(1958,1959)$ has given full accounts of "tropical ataxic neuropathy" in Nigeria. The neurological picture was similar but $96 \%$ of his cases showed mucocutaneous lesions suggesting vitamin-B deficiencies. He noted marked loss of vibration and joint sense in most cases and precipitation of the disease by fever, pregnancy, and diarrhoea. The same author (personal communication, 1962) reported abnormal pyruvate metabolism in the majority of these ataxic cases which reverted to normal when thiamine and vitamin $\mathbf{B}$ co. were given.

Cruickshank (1956) describes similar cases from the West Indies, but $93 \%$ of his patients showed evidence of an upper motor neurone lesion.

The present series of cases is small and neurological disturbances are similar to those previously described. However, the absence of mucocutaneous lesions, the absence of upper motor neurone signs, and the presence of constipation appear to be minor variations from most other series.

The cause of these ataxic syndromes is still not proved, but most authors consider them to be nutritional deficiency diseases and record some improvement with vitamin B therapy.

The improvement of our patients on the hospital diet and vitamin B suggests that the illness is probably due to a vitamin-B deficiency of some kind. In the present conditions of food shortage in Tanganyika and Kenya it is quite likely that other cases will appear.

\section{Summary}

Seven cases of an ataxic neurological syndrome in Tanganyika are described. This series is believed to be the first reported from East Africa.

The condition comprises sensory ataxia sometimes combined with optic atrophy and nerve deafness. Motor power was normal and mucocutaneous lesions were not seen.

The disease was considered to be nutritional in origin, and some improvement occurred with hospital diet and the vitamin-B group of drugs.

We thank the Chief Medical Officer, Tanganyika, for permission to publish this paper; Dr. J. Vella for the audiograms; Dr. J. B. Woodall for virus antibody tests; Dr.
U. J. Patel for checking the eye findings; and Dr. G. L Monekosso (G. L. Money) for literature and information.

REFERENCES

Bradley, J. T. (1929). Annual Report on Md. Dept., Seychelles. Abstracted in Bull. Hyg. (Lond.), 1929, 4, 391.

Buchanan, J. C. R. (1932). Trans. roy. Soc. trop. Med. Byg., $25,283$.

Cruickshank, E. K. (1956). W. Indian med. J., 5, 147.

Garland, H. E. (1946). Proc. roy. Soc. Med., 39, 178.

Money, G. L. (1958). W. Afr. med. J., 7, 58.

(1959). lbid., 83.

Pallister R. A (1940). Trans, roy. Soc. trop. Med. Hyg., 34, 203. Scott, H. H. (1918). Ann trop. Med. Parasit., 12, 109.

Spullane, J D. (1947). Nutritional Disorders of the Nervous System Livingstone, Edinhurgh.

Stannus, H. S. (1936). Trop. Dis. Bull., 33, 729, 815, 885.

Walters, J. H. (1953). Quart. J. Med., 22, 195.

\section{HIGH-LEVEL MALIGNANT OBSTRUCTION OF COMMON HEPATIC DUCT TREATED BY PERMANENT INTUBATION}

BY

\author{
R. R. HUNTER, M.B., B.Chir., F.R.C.S.Ed. \\ Consultant Surgeon, Ashford and Willesborough \\ Hospitals, Kent \\ AND \\ S. A. ZAHEER, M.B., B.S., B.Sc., F.R.C.S. \\ F.R.C.S.Ed. \\ Surgical Registrar, South-east Kent Group of Hospitals \\ Ashford, Kent
}

Extrahepatic biliary obstruction by carcinoma is most commonly caused by a growth in the head of the pancreas or in the ampulla. Next in order of frequency the site of neoplasm may be the common bile-duct proper, the junction of the cystic, common bile, and common hepatic ducts, followed by a hepatic duct and the cystic duct (Rolleston and McNee, 1929 ; Kirschbaum and Kozoll, 1941 ; Gray and Sharpe, 1941 ; Neibling et al., 1949; Glenn and Hays, 1953). The following case of obstruction of the common hepatic duct was caused by malignant extension into lymph nodes surrounding this duct at the porta hepatis, the primary tumour being in the head of the pancreas but not large enough to cause biliary obstruction at that site.

\section{Case Report}

A man aged 80 was admitted to hospital on May 9, 1961, with a history of sudden onset of jaundice ten days previously; this was progressive and his urine had become dark and concentrated and his stools pale; he was aware of some loss of weight and abdominal discomfort not amounting to pain. Pruritus, nausea, vomiting, diarrhoea, and melaena were not present. On examination he was a frail elderly man, deeply jaundiced, with a temperature of $99^{\circ} \mathrm{F}$. $\left(37.2^{\circ} \mathrm{C}\right.$.). There was tenderness in the epigastrium, and the liver was enlarged two fingerbreadths and tender. There were no palpable glands and no evidence of free fluid; the gall-bladder could not be felt. A diagnosis was made of obstructive jaundice, presumably caused by carcinoma of the head of the pancreas.

Investigations. $-X$-ray examination of the chest and abdomen, N.A.D. Hb $90 \%(14$ g. $/ 100 \mathrm{ml}$.). E.S.R. $22 \mathrm{~mm}$. (Westergren). W.B.C. $9.700 /$ c.mm. (N. $86 \%$, E. $0 \%$, B. $1 \%$, L. $13 \%$ ). Liver-function tests : serum conjugated bilirubin $7 \mathrm{mg}$. $/ 100 \mathrm{ml}$. ; serum alkaline phosphatase $46 \mathrm{~K}$.A. units; thymol turbidity 1 unit; zinc sulphate turbidity 8 units; serum acid phosphatase 0.8 unit. Serum diastatic index 10 . Urine : urobilinogen-positive ; bilirubin-strongly positive ; bile salts-negative. 